Note: This is a pre-publication final draft. For the published version, please see: Rafalow, Matthew H. and Adams, Britni L. (2016). "Navigating the Tavern: Digitally-Mediated

Connections and Relationship Persistence in Bar Settings." Symbolic Interaction 40(1): 25-42.

\title{
Navigating the Tavern: Digitally-Mediated Connections and Relationship Persistence in Bar Settings
}

Matthew H. Rafalow

University of California-Irvine

Britni L. Adams

University of California-Irvine

The widespread adoption of digital communications technologies has provided new avenues for social interaction to occur. We build on the sociological literature of fleeting encounters in bar settings to show how patrons' use of these technologies augments the bar experience and shapes the social networks that may develop through interaction. Using seven gay, lesbian, and heterosexual bars located in Southern California as research sites, we describe how patrons invoke digital technologies as props to aid the impression management strategies used to facilitate new connections. Second, we demonstrate how these encounters are subject to greater relationship persistence as a result of the way these technologies are used to quickly create a shared history. We conclude by arguing that fleeting encounters are no longer connections that either persist or completely fade away after face-to-face interaction. Rather, they often persist through technology-mediated communications in ways that result in, at minimum, the development of weak ties. This greater relationship persistence can permit more opportunity to get to know a potential partner in digitally mediated settings like Facebook or via texting, but it could also require new strategies to evade interested others given this new lack of ephemerality and the influx of weak ties.

"Fleeting encounters" occupy a unique position in sociology. This small but thought-provoking literature documents how seemingly serendipitous meetings are actually structured by various conditions that differently inform relationship persistence (Allon 1979; Cloyd 1976; Davis 1959; Goffman 1959; 1967). Often these studies take place in bar settings - the "ultimate" context to observe fleeting contacts - as a way to observe and reflect on their contribution to a key sociological question: how are networks formed? For example, ethnographers illustrate how gendered impression management strategies are linked to the formation of new romantic partnerships, and determine whether social ties are formed or not (Allon 1979). Scholars who study partner selection and marriage know that these fleeting but potentially intimate connections are features of network formation and social reproduction at large (Laumann et al. 2004; Liebow 1967; Simmel 1949; Swidler 2001; Waller 1937).

Research on fleeting encounters has not, however, explored how these face-to-face interactions may be differently structured since the advent of ubiquitous communications 
technologies. What research exists is a burgeoning literature on online dating, which documents not only the prevalence of internet use to seek out potential mates (Madden and Lenhart 2006; Rosenfeld and Thomas 2012) but also how daters negotiate their interactions online in an attempt to secure potential partners (Gibbs et al. 2006; Elison et al. 2006). This work illustrates how online daters, too, invoke impression management strategies with regard to how they present themselves online in order to garner interest (Gibbs et al. 2010). But we are still left to wonder how digitally-mediated face-to-face encounters may translate to new partnerships.

We begin to answer this question through an ethnographic study of the use of ubiquitous technologies in the contemporary tavern. As we will demonstrate, the use of digital technologies in bars provokes revision to existing work on dating and fleeting encounters in-person. We find that patrons use digitally-inflected impression management strategies to develop weak ties that do not require much social work to sustain but do require considerable effort to completely sever. Relationship persistence can permit more opportunity to get to know a potential partner in digitally mediated settings like Facebook or via texting, or it could require new strategies to evade interested others given this new lack of ephemerality and tie persistence.

\section{Dating in the Twenty-First Century}

We are witness to an explosive rise in scholarship over the last decade on dating online. This literature illustrates that dating and partner formation, at least in the U.S. context, is increasingly digitally-mediated (Madden and Lenhart 2006; Rosenfeld and Thomas 2012). Although this work contends that the use of digital tools, like online dating applications, reduces geographic limitations to developing new partnerships, scholars increasingly show that daters must navigate symbolic orders in order to make these connections. For example, Ellison et al. (2011) argue that online daters create versions of themselves in their profiles and in their digital interactions that are presumed to be attractive to others. Daters" "versions" could include purposefully misreported age, weight, or height, or exaggerated interests in fitness activities. These self-presentations are strategic disclosures, also referred to as impression management strategies, designed to portray the self in a way that meets situated expectations (Goffman 1959). Ellison and her colleagues ultimately argue that daters present a self in line with a "profile as promise," or an impression that emphasizes normative ideals but does not stray far from the reality of both their personality and their physical selves should a face-to-face interaction occur.

Although scholarship on online dating assumes that these platforms are the presumed gateways to an eventual face-to-face encounter, scant research exists that explores how digitallymediated, in-person exchanges actually occur. An exception is a recent study of Grindr use (a gay dating/hookup phone application) among gay men that suggests varied social circumstances, online and face-to-face, drive why people delete the app (Brubaker, Ananny, Crawford 2014). But by and large online dating literature suggests that face-to-face encounters are less subject to social forces like impression management than in the online context (Ellison et al. 2011). Digital media scholars argue that the information one provides online is more malleable and selective than in face-to-face interaction because only verbal and linguistic cues are the primary displays online (Walther 1996). Most existing scholarship on online dating provides support for the notion that daters use digital tools to construct particular selves online that increase the likelihood of encounters translating into a stronger connection. As we describe next, the 
literature on face-to-face encounters in bars indicates that impression management strategies would be alive and well in the twenty-first century tavern, too.

\section{Fleeting Encounters and 'Props' for Impression Management}

Research on in-person fleeting encounters provides an interesting companion to work on online dating, and shows how "chance" interactions are structured despite their brevity and occurrence with unknown others. The bulk of research on fleeting encounters occurs in bar settings and explores how fleeting encounters matter for social network formation. In a bar ethnography, Cavan (1966) argues that bars provide a structure unlike any other where fleeting encounters could potentially translate into different types of relationships: friendships, sexual partners, and longer-term romances. This literature, while aged, provides inroads for understanding how partnership formation may occur in the contemporary tavern.

Like studies of online dating, work on pairing rituals in bar settings primarily focuses on patrons' use of impression management strategies to translate fleeting encounters into new ties. But bar studies indicate that, like people who meet online, there is still much unknown about interested others in bars. As a consequence, patrons adopt various impression management strategies that are appropriate to the bar context in order to transform a fleeting encounter into a stronger connection (Allon 1979; Goffman 1959; 1967). For example, an individual who is well versed in the norms of a setting will invoke certain styles of talk to achieve an ideal outcome. Bars, like other environments, are social fields that have durable sets of rules and etiquettes that guide interaction (Clinard 1962; Clough 1979; Grazian 2007; McFarland 1974; Moore 1897). Patrons who know the "rules of the game" in the bar are not only more successful at forming new ties with other patrons, but they are more likely to become "regulars," or part of the collective memory of the community (Cloyd 1976; Katovich and Reese 1987). Studies have shown that men who learn bar etiquette through considerable practice over time are considered "smooth" and are successful at forming new ties. Often, these pairings begin with an initiation of contact, a negotiation of interests between two people, and decisions about relationship persistence. Research indicates that this process is laden throughout with gendered impression management strategies where patrons aim to put on their "best face" to achieve the type of pairing they desire. If, however, one or more participants in this process are uninterested, new ties do not occur.

These studies also show that bar patrons often use props as part of their impression management work. For example, much existing research on pairing rituals in bar settings focuses primarily on how patrons use the physical bar infrastructure to their advantage to translate fleeting encounters into new ties (Allon 1979; Cloyd 1976; Goffman 1959; Snow, Anderson, and McCall 1991). Patrons use bars, tables, gaming areas, bathrooms, and dance floors in ways that facilitate pairing. For example, men and women "stake out" territory at the bar and at tables to hang out with their friends and observe the crowd for potential partners. In addition to "biological" relief, bathrooms are used to "gussy up" and look appropriate for flirtation. Gaming areas, like pool or arcade games, are places where men show off their skills and initiate conversation among bystanders. And dance floors are often arenas where men approach women to dance and make physical contact (Cloyd 1976; Grazian 2007).

From this literature we would expect that many of these impression management strategies persist as part of patrons' relationship formation processes in bar settings. This stands 
in contrast to the literature on online dating which presumes more "truth" from greater physical cues in-person. However, we may also expect that in today's era, props could include digital technologies as part of impression management and relationship formation. We next turn to human-computer interaction research to explore this possibility.

\section{Digital Technology and Relationship Persistence}

Social scientists who study digital technology argue that new technologies, such as mobile phones, have become ubiquitous and deeply embedded in the everyday practices of people in a variety of contexts (Dourish and Bell 2007; Ito et al. 2006; Weiser 1993). A number of such researchers contend that digital technologies dramatically increase the odds that users form new relationships, both locally and globally. Although these studies do not consider dating and romantic partnership formation, they suggest that people form new ties online (Tufecki 2010), have greater contact with friends and family, relative to nonusers (Wang and Wellman 2010), and use social media, like Facebook, to increase network diversity and sustain these contacts (Steinfeld et al. 2008). Of note for the purposes of this study, some scholars argue that digital technology use is associated with the development of more weak ties, or social relationships that are more acquaintances than developed relationships, in their local settings (Granovetter 1983; Hampton et al. 2010; Hampton and Wellman 2003; Wellman et al. 2001). We may therefore expect that digital technology use in the case of bar settings may lead to an expansion in developing weak ties through connections made, and at least weakly fortified, using technology.

Studies of digital technology use and social networks have not, however, explored how people actually use technology to facilitate social network development. Much of the work that exists on the topic of digital technology and network diversity necessarily uses quantitative methodology to determine how prevalent digital technology use is associated with network expansion (Hampton 2007; Marlow 2005; Steinfeld et al. 2008). While informative, this imposes limits to understanding how this use of technology matters in daily lives and changes the ways in which people seek romantic partners. We expand this work by drawing on ethnographic methods to illustrate how social ties develop with these internet-connected tools (Putnam 2000). Ethnographic methods permit the researcher to illustrate how, for example, people may adopt digital technologies as props for their overall aims. Technologies like smartphones may be used as props to aid patrons' impression management strategies, and assist in the formation of social ties. In this study, we find that in the digital era, interactions in bars are less often ephemeral. Patrons use digital technologies as props to supplement impression management and more easily develop weak ties, minimizing the likelihood of a fleeting encounter. As a consequence, patrons must adapt their pairing strategies both to pursue and resist romantic advances through different mediums after the face-to-face interaction.

\section{Method}

Bar Settings

Although existing research has examined how ubiquitous technologies are used in a variety of contexts, the field sites where these practices are examined are often limited to a certain range of interaction as dictated by the norms of the site of study. Bar settings are unique and ideal field sites through which to examine highly varied kinds of interaction, including 
fleeting encounters and the formation of new social ties. Scholars have used these research sites as places to study the establishment of interaction orders that have meaningful impacts on how drugs and violence (Duff 2005), gender (Snow et. al. 1991), sexuality (Green 2008; 2011), sex work (Lofland et al. 2005) and emotional labor (Pasko 2002) are negotiated. Cavan (1966) observed that interactions, such as advances, or "pickups," occur more frequently in bars than any other setting, such as beaches, parks and streets. Through observation of interaction in bar settings we can assess whether and how the use of technology could have new and meaningful implications for how people negotiate face-to-face interaction.

\section{Research Sites}

Our aim in the selection of research sites was to identify bars that offer variety across location, populations served by the bar, and physical infrastructure. Much existing work focuses only on heterosexual establishments, and so we intentionally selected more diverse empirical sites to document patterns across a number of variables. As shown in Table 1, we selected seven bar sites that variously market to heterosexual, gay male, and lesbian clientele and are in urban or suburban regions. Our selection of research sites was not intended to include an exhaustive list of social statuses; however, we aimed to select across a few basic characteristics to observe the widest range of interactions possible.

( Table 1 about here )

\section{Data Collection and Analysis}

Although ethnographic studies are often reflexive in nature, we took seriously our own social position as an opportunity for both data collection and reflection. In fact, ethnographers who take to bar settings often comment in their writing about the various kinds of data they obtain as participants. Bochner and Ellis (1997) find that their experiences in bars informed their own self-perceptions by assessing their reactions to others' provocations. Allon (1979) reflects that her own entry into bar settings resulted in alienation because she realized her "newcomer" status and gender relegated her to the margins of the bar. And, in a strategy we follow for our own study, Snow, Robinson and McCall (1991) monopolize on their own participation in fleeting bar encounters as a means to collect valuable data. In addition to observations and interviews, the authors participate in the pairing process as a means to collect data that would be impossible to obtain otherwise.

As argued in other scholarship (Morrill et al. 2005; Snow \& Anderson 1993), our teambased data collection allowed us to triangulate observations from the same visit. We also were able to adopt multiple roles that allow for greater flexibility in terms of negotiating barriers to access that is normally experienced by lone researcher fieldwork. Each researchers' social status presented different challenges and opportunities to engage with a wide variety of bar clientele. One researcher is a 20-something White gay male, and the other is a 20-something White heterosexual female. As a result, we were able to garner different kinds of attention in these bars than if both researchers were of the same gender, expanding the range of interactions possible in those settings.

Data were collected through two means: participant observation in a number of different bars, and informal conversational interviews with patrons in those settings. All names used in our 
results are pseudonyms. Participant observation through team ethnography was conducted during a seven-month period in which both authors visited the research sites together, with all but one site visited multiple times. On each visit, we began by standing or sitting in a location that had as expansive a view of the bar setting as possible. This enabled us to observe a wide variety of interactions that occur in different structural locations of the establishment, such as on a dance floor, by the bar counter, or near pool tables. Most nights, we would attempt to vary our location and our own group dynamic. We would move to other parts of the bar, sometimes together, sometimes alone, to observe how our group composition shaped the kinds of interactions we could not only observe but also became engaged in with other patrons.

Observing technology use in bars was not difficult. As we will discuss, many people frequently used cell phone technologies by themselves and in interaction with others. We followed a routinized pattern to obtain informed consent whenever interacting with other bar patrons. First, we introduced ourselves as researchers with interest in studying bar dynamics, including digital technology use and romantic encounters. We brought this up repeatedly at the beginning of our interactions with new patrons, during our exchanges with them, and took field notes with them as we interacted with them at the bar. We found that patrons were overwhelmingly interested in our study and would share their thoughts on the matter. Sometimes during these exchanges patrons would pursue potentially romantic connections with us. Although these interactions provided incredibly rich data on more intimate uses of technology that could not have been obtained by any other means, they certainly provoked ethical considerations (Dingwall 1980; Snow et al. 1991).

After reflecting on early bouts of fieldwork with such engagements, we decided that the most appropriate means to avoid exploitative relationships with patrons was to not only be up front about our research but also adhere to the situated standards by which to engage with interested others. In other words, we very quickly learned that patrons, and particularly men, approach others to flirt all the time. To interact with those making such advances without expressing romantic or sexual interest was appropriate and not considered an unethical breach of these relationships in the context of the bar. For example, we observed men flirting with women who were romantically uninterested but conversed with them for some time, and they were not expected to pursue anything more with these men despite their advances.

Data analysis occurred throughout the data collection process and continued after data collection was complete. We began with an analytic induction model, or outlined several hypotheses about digital technology in bars as suggested by the literature, before collecting our data (Manning 1991). We held debrief meetings after every stint in the field, and through these discussions revised our hypotheses as data emerged (Bogdan and Biklen 1992). As with much qualitative work of this nature, results led to additional questions or hypotheses in the field that required more fieldwork for clarification. Among these questions included the validity of our findings; our team-based strategy permitted us to go back into the field and triangulate what we observed between each of our vantage points (Ambert et al. 1995).

\section{Results}

In this section we explore the relationship between patrons' use of digital technologies and the formation of new ties via pairing rituals in today's bar settings. This data provides indepth detail for patterned experiences we observed in these environments that informed the 
pairing process. First, we provide a descriptive contrast to existing bar literature by revealing the extent to which digital technologies have become ubiquitous and central to bar life. Second, we illustrate how patrons use digital technologies as props to enhance their impression management strategies when pursuing new connections. Lastly, we show how these digitally-inflected interactions transform into weak ties.

\section{The Contemporary Tavern}

The bar settings that we studied for this project included many of the infrastructural features described by existing literature, but we found that most of these spaces were also now augmented by digital technologies. For example, the bars all shared similar physical spaces, including bar counters, tables, gaming areas, and dance floors. Patrons would congregate in groups in each of these areas to chat with one another, order or consume alcoholic beverages, and dance. As we will discuss, we found that these physical spaces were still important to the pairing process, but bars now often include new technologies as part of their architecture.

The typical bar experience begins by checking in with a bouncer, or gatekeeper, at the entrance of a bar. Patrons would show their driver's license to the bouncer to prove they were of legal drinking age and then would walk through into the main entrance, having gained access. Each bar followed similar flows of bar-goers in and out of the establishment over a period of each night. For example, most bars were fairly empty around 9:00pm but gradually increased in patronage until their highest capacity at $11: 00 \mathrm{pm}$. After this time the number of bar guests would decrease until the bars closed between 1:00am and 2:00am. All of the bars we studied were host to similar group dynamics among patrons. With the exception of some who appeared to come alone, most people arrived at the bar with a group of people and spent the bulk of their time socializing with this group.

A first major contrast from thick descriptions of bars in existing work was that television screens in these bars were internet-connected and used as communications devices. These screens were large monitors that hung along walls where patrons usually congregated, like over bar counters or along the walls of a dance floor. During peak hours, monitors all had scrolling text on their screens. Listed next to each each piece of scrolling text was a cell phone number. Bar patrons could send text messages to an advertised number on the screen and their message would be listed on the television screens placed in plain view around the whole bar for all to see. Although the television screen listed cell phone numbers, the exact identities of the message senders were unknown to the bar public unless the content of the message said otherwise. In one example, two people texted messages to the monitor:

"Watching the DJ dance with John is so cute, they are so cute together!"

"John n Dave are dicks."

"I've seen it - it's BIG!"

In the above messages that displayed on the screen, two people dancing at the bar were publicly identified and discussed by others at the bar. The technological infrastructure of the television program enabled patrons with cell phone access to transmit messages across the entirety of the bar. Conversations between several people became public to the bar through the use of cell phone technology. People at the bar would occasionally look at the television screen, and when 
particularly sensational content from others appeared, groups would point at the television, laugh, and offer commentary. Patrons used this technology at the bar to comment on others they find attractive, or to share small group experiences with the entirety of the venue. In this way, the technology on the bar itself was a platform to identify and communicate with others.

Perhaps the most striking contrast to descriptions of bars in the extant literature is that nearly every patron carried a smartphone (such as an iPhone). At no point during peak hours at the bar could one not see smartphones being used in plain view. While patrons pulled out their smartphones when they were alone at the bar, they were also used within the group context, as well. Patrons would use smartphones to take pictures or video recordings of themselves or others in the group; to show photos to others; to send text messages; make phone calls; or use any number of other applications on their phones. We later go into greater detail how and why patrons used phones and other technologies the ways that they did. But the prevalence of ubiquitous technologies in these bar settings is a notable shift from earlier bar studies.

While new technologies were embedded in the physical space of the bar, applications on ubiquitous cell phones augmented face-to-face pairings, as well. Global positioning system (GPS) technology on cell phones enabled users to see photos of others who were geospatially nearby, permitting chat conversations between users. We found that gay men, especially, used these applications to chat with their friends as well as to find interested others online. In one example we observed a group of gay men interact around and through an application called Grindr. "Someone's on Grindr!" said a male patron to his friend at the gay bar. The friend pointed to a picture on his phone. "Oh look, you're on it too!" he retorted. "There. I just messaged you." His friend looked at the message on his own phone and proceeded to read aloud the word "slut." They all laughed and then proceeded to point out photos of other men on the app that they thought were attractive.

GPS-enabled smartphone applications provided additional means to find and communicate with people who were nearby. Technologies that were built into the physical infrastructure of the bar, as well as applications that provided additional means to find and interact with others, presented opportunities for encounters that are new to the bar literature. Next, we explore the strategies that patrons used to pursue connections in more depth. As we discuss, digital technologies were used as props for impression management.

\section{Digital Props for Impression Management}

Like many other settings in our society, digital technologies permeate the contemporary tavern. However, we find that impression management strategies are still central to relationship formation in bars (Allon 1979; Goffman 1959; 1967). Patrons used digital technologies as props to pursue their desired intents to translate a fleeting encounter into a more durable relationship. To illustrate this point, we provide a detailed vignette between one researcher and Carlos, a patron. Carlos used his cell phone to convey a set of "best faces" to negotiate the relationship, a recurring pattern we saw among patrons. This vignette was assembled after analyzing fieldnotes taken from observations by the male researcher and reflective notes by the female researcher. Thereafter, we explicate this process with excerpts obtained through interviewing by comment as these types of interactions occurred in situ (Snow et al. 1982).

Both researchers were at a heterosexual bar when Carlos approached the female

researcher and asked her to dance. His request took her a bit by surprise, but she left the other 
researcher and went to dance with him. "Did I scare you when I asked you to dance?" he asked while they danced. "To be honest, I was so caught off guard I couldn't find a reason to decline!" she replied. Over the course of dancing, he continually asked questions to get to know her, like what she studied in school and if she comes to the bar a lot. The song neared its end and patrons' dancing began to slow down. "Would you dance with me again?" he asked. "I promise not to sneak up on you like before!" She agreed to dance again later in the evening, and they split off and she returned to the other researcher. She wondered about his exact intentions and, at times, felt swept up into continued interactions with him when he caught her off guard with requests to communicate. In keeping with existing research, his extensive experience as a member of the bar likely tied to his success at facilitating continued contact with the researcher.

Just under an hour later, Carlos approached the female researcher once again and the two talked more. This time, the researcher took more initiative to ask questions about his biography. "So what do you do for a living?" she asked. He smiled. "Let me show you." He then took out his phone and opened different images of artwork to show her. "I'm an artist. I work for gaming companies to produce art, but lately I've been doing artwork for schools." He swiped through photos on the phone screen to show her a picture of a little yellow robot that he created recently for a school. Later in conversation, he expressed that he is "going to be a proud uncle for a minute" and opened images of his nephew on his phone to show the researcher. Shortly thereafter, he used his phone again to "really show his geekiness," and opened pictures of his nephew dressed as a character from the Star Wars movies, and himself in a costume of Captain Jack Sparrow from the films, Pirates of the Caribbean. "I love Star Wars and used to watch it with my dad," the researcher explained. After seeing these pictures, she felt like the conversation got more personal; it presented a more multidimensional impression of Carlos than was limited to their exchanges previously. In this way, Carlos used his phone as a prop to strategically present versions of himself that include his professional and familial identities.

After a few more minutes of looking at some of the pictures on his phone, Carlos asked her if it would be too forward to ask her for her phone number because he was enjoying their conversation. "We could talk more about Sociology and this study over coffee," he said, smirking. He took out his phone again and opened an application to take notes, and wrote down her name and number. She left to return to the other researcher, and both left the bar soon after.

This narrative of exchanges between the female researcher and Carlos illustrated familiar themes from existing research on bar settings, but also some new features to relationship formation as a result of the use of ubiquitous technologies connections. In keeping with existing research, Carlos' extensive experience as a member of the bar likely tied to his success at facilitating continued contact with the researcher. But our research indicates that digital technologies are now used as props to aid in patrons' impression management strategies. This vignette illustrated how ubiquitous technologies like smartphones provided new avenues for people to show their "best face" to potential new connections. Carlos used his smartphone as a toolkit to present himself as an artist, a caring uncle, a "geeky" Star Wars fan, and someone who can be silly and dress up, even as an adult. In this way, the phone was used to provide impressions of Carlos' personality and commitments that are external to the bar itself.

Other patrons reflected, too, on the use of digital tools as props during the pairing process at the bar. One interlocutor was privy to the exchange between Carlos and the researcher. "That's actually a really smooth strategy," she said. "Using photos of little kids to flirt with a girl, very smooth. Great way to hide the fact that he probably has slept with every woman at this bar." Cell 
phone use in this way could be conceived as a strategy for impression management that helps negotiate romantic interests despite other features of a patron's background that may make a new connection more difficult. "I mean, I've probably done it too," said an interlocutor about using photos when talking to a guy at a bar. "You want them to see another side of you beyond what you can just say with words." Digital tools can function as props that convey symbolic meanings about one's self to others in the hope that it will aid in the development of a new social tie.

Bar participants explained that using digital tools for impression management requires a degree of social sophistication. "Sometimes it's tricky to use these dating apps while at a bar," said one patron about a GPS software application. "It takes some skill to know how to say the right things on the app and then in-person, because you don't want people to get the wrong idea about you." Putting on the "best face" in not just digitally-mediated contexts but also in traditional face-to-face interaction mattered for establishing trust and interest between two people. Bar participants also reflected that it is important to know when and when not to use digital tools for the pairing process to be successful. "You have to decide when you should use your phone," said another patron. "If I'm using it on the dancefloor a girl could get pissed because she thinks I'm talking to someone else." In another interaction between two young men on the dance floor, one swatted the other's phone while he was using it. "Be in the moment, man!" he exclaimed. Cell phone use triggered a breach of expectations, and that attention should be about dancing, not the phone, to facilitate face-to-face interaction with possible partners. Phone use signaled particular meanings to other people at the bar, and while sometimes using a phone could communicate a lack of interest, other times not using a phone meant you were uninteresting. For example, not using a phone when by one's self could signal they are a loner. "I mean, sometimes I pull out my phone when my friends haven't gotten here yet because I don't want to look like a loser," said a patron. "If a girl sees you just standing there looking like you have no friends it's not going to help."

In this section, we illustrated how digital technologies were used as props to aid in the pairing process, translating a fleeting interaction into a stronger social tie. Both the extended vignette and patrons' explanations of these uses of digital tools illustrate how tools can be used to put on a "best face" to meet situated expectations of ideal types of interactions with others. In the next section, we provide examples of how digital technologies are used after moments like when Carlos requested that the researcher stay in communication. We discuss how digital technologies were used to translate fleeting encounters into greater relationship persistence. Navigating the Tavern: From Fleeting Encounters to Weak Ties

While digital technologies augment the bar environment by providing new ways to meet and negotiate interests between potential partners, the design of these technologies enables greater relationship persistence than ever before. As we will demonstrate empirically, bar patrons used digital technologies in ways that formed, at minimum, weak ties through technologymediated platforms. However, a potential consequence of the formation of weak ties through this means was increased awkwardness if the negotiation of interests does not go well. Thus, patrons used technologies in ways that quickly translated fleeting connections into weak but durable ties that may not necessarily amount to strong ties.

Both researchers were at a bar serving gay men and at a certain point in the evening another patron named Joe approached the male researcher. Joe walked from one side of the bar where he was hanging out with his friends to a table where we were seated and introduced himself. He told us about his job and fun things he likes to do in the area. Talking continued with 
the three of us for roughly fifteen to twenty minutes when Joe changed the conversation and looked directly at the male researcher. "Hey, I think we should talk again," he said. "I want to give you my number." The male researcher reached into his pockets, but could not find his phone. "I didn't bring my phone with me tonight, I'm really sorry," he said. Joe gave him his phone and asked him to enter his phone number on the device, and he subsequently entered his contact information into Joe's phone. A few minutes later, both researchers disengaged from the bar to leave.

On the drive home the male researcher found his phone in the car and saw that he had a number of text messages from him. "Hi Matt, it was so nice meeting you :)" he said to the researcher in a message. "You, too!" the researcher replied, and Joe texted again to continue the conversation they were having at the bar. Often, the texts would come in short bursts of messages back and forth between Joe and the researcher and then stop until the next day when Joe sent other messages to continue conversing. Smartphone technology thus enabled conversations to continue beyond the bar setting asynchronously, allowing fleeting bar encounters to translate into the formation of persisting weak ties through contact information sharing and the communications platforms.

Other patrons reflected on their experience with this post-bar texting practice, noting that it can have positives or negative outcomes depending on how interested they were in the person communicating with them. "If you like them it's great," said one patron. "You don't have to worry about losing their number because it's so easy to find and message them." A friend of this patron chuckled. "And if you don't like them it's annoying as hell," she said. "It means they can keep messaging you forever and you have to decide when to stop responding." Thus, while fleeting encounters are quickly translated into weak ties, such connections provoke greater "work" to manage this relationship.

The greater relationship persistence through the design of these technologies did not always result in the formation of stronger ties. Carlos, the patron mentioned in the vignette earlier, also exchanged contact information with the researcher at the end of their first conversation. Their interactions subsequently occurred online through texting, but their communications did not last. After they left the bar that evening Carlos sent a series of text messages to the researcher. "I had such a good time meeting you," he texted her. "Me too, thanks," she replied in response. The next day he texted her again. "How about we get a coffee?" he asked, but she declined. After she said no, his digitally-mediated communications stopped. Thereafter, during visits to the same bar where we met, he also ceased face-to-face communications and actually avoided making eye contact with her. Although both Carlos and the researcher were connected through their smartphones in the form of a weak tie, their relationship did not become stronger, nor continue in-person.

Patrons who used online dating apps while at bars also expressed that the weak ties they quickly developed through them did not always develop into something more. One interlocutor used a GPS dating application on this phone, and checked it frequently throughout his night at the bar. "One of the guys I've been chatting with on our app is here," he said quietly, pointing him out to me. After a moment, his phone vibrates. "He just messaged me again and said, 'Why haven't you said hello yet?"' GPS applications such as these enabled a very fast forming social connection online, yet use of this digital tool to communicate created new ambiguities to be negotiated face to face. The interlocutor and I both noticed that the guy he pointed out and chatted with had walked past without paying us any attention. "That's so weird," said the 
interlocutor. "He just said he saw me online, and now he isn't even saying anything." Several minutes later, the guy came back and starts a conversation with the interlocutor. After about five to eight minutes, he leaves. "I am so glad that's over," the interlocutor said.

Online applications for pairing, like offline encounters, are not always successful at facilitating deep connections. But these digital tools do enable greater relationship persistence as patrons' make easy use of these technologies to create weak ties. The technologies create new ambiguities, too, through the availability of data and persistence of communications data via the application. Daters can be embedded in networks that are hard to evade ("Why haven't you said hello yet?"), as well as forced to navigate impressions using the information obtained online in the application, as well as in the face-to-face setting.

\section{Discussion}

Past work on "fleeting encounters" demonstrates that social forces located in the context where these interactions occur structure relationship formation (Allon 1979; Cloyd 1976; Davis 1959; Goffman 1959; 1967). For example, research on fleeting encounters in bar settings finds that the physical infrastructure of the bar, as well as established etiquettes for approaching people, inform whether new relationships are formed (Clinard 1962; Clough 1979). Using data collected during participant observation in seven bar settings, we illustrate how encounters in the contemporary tavern have changed. We find that existing research does not fully explain how fleeting encounters are negotiated since the proliferation of digital technologies, like ubiquitous smartphones. These new technologies augmented the experiences of patrons in these settings by presenting new ways to find and interact with potential partners, including the use of digital tools to help develop greater relationship persistence in the form of weak ties, requiring different social navigation than traditional understandings of fleeting encounters.

First, we provide a contrast to existing bar literature by revealing the extent to which digital technologies have become ubiquitous and central to bar life. Bars were equipped with internet-connected television screens that allowed patrons to send messages that can be displayed to the entire bar. Patrons also use digital devices, like smartphones, to communicate with others in and outside of the bar. Additionally, patrons used social networking services designed to facilitate romantic connections at the bar. Digital technologies were a central facet of the bar infrastructure and informed its capacity for interaction.

We also found that, contrary to work on online dating, in-person bar patrons actively engage in impression management and use digital tools to do so. Specifically, patrons used digital technologies as props to aid in their impression management strategies (Goffman 1959; 1967). For example, smartphones were used as tools to display other facets of their character or personality that they could not otherwise show within the bar context. Using digital tools to put on a "best face" was challenging, and required situated knowledge about how to use these tools within expected parameters of pairing.

Lastly, we illustrate how patrons' use of digital technologies facilitated greater relationship persistence. In existing work, fleeting encounters in bars were either transformed into a relationship or quickly faded into the ether. Instead, we show how digital technologies were used to create connections with others, such as via texting or on social media platforms, and we find that fleeting encounters were often translated into, at minimum, weak tie formation. This did not mean, however, that these weak ties became something greater. In fact, these weak ties 
sometimes created awkwardness when one or more parties want to end the relationship. This suggests that impression management may be a key facet of digitally mediated communications for both those who pursue and resist the cultivation of weak ties into stronger ones. And, consequently, it may require the development of a generalized social etiquette around weak ties ("Is it too rude to 'unfriend' someone I met once?").

Sociological research on fleeting encounters and social network formation more generally should consider how technology-mediated communications alters our existing understanding of these environments. Although fleeting encounters in the literature were limited to taxicab rides and bar exchanges, we are witnessing an era where digital technologies are used to facilitate such connections. For example, newer video game platforms put players from around the world into collaborative games with others they do not know; ride-sharing software connects strangers for drives to their destinations; and online applications connect unknown others with shared interests to attend events like concerts. How do people navigate these digitally mediated settings? How might they lead to the development of new relationships? How might people develop new strategies to sever weak ties since, or do they even try? Social scientists have a terrific opportunity to explore how social phenomena animate particular uses of digital technology in ways that matter for social network formation. 


\section{References}

Allon, Natalie. 1979. “The Interrelationship of Process and Content in Field Work." Symbolic Interaction 2(2): 63-78.

Bochner, Arthur P., and Carolyn Ellis. 1997. "Fragments of Self at a Postmodern Bar." Journal of Contemporary Ethnography 26(3):251-292.

Brubaker, Jed R., Mike Ananny, and Kate Crawford. 2014. "Departing glances: a sociotechnical account of 'leaving' Grindr." New Media \& Society.

Cavan, Sherri. 1966. Liquor license: An ethnography of bar behavior. Chicago: Aldine Pub. Co.

Clinard, Marshall B. 1962. "The public drinking house and society." In D. Pittman and C. Snyder (eds.) Society, Culture, and Drinking Patterns. New York: John Wiley.

Clough, P. 1979. "Sociability and public behavior in a mid-sized city." Studies in Symbolic Interaction 2: 359-376.

Cloyd, Jerald. 1976. "The Market-Place Bar: The Interrelation Between Sex, Situation and Strategies in the Pairing Ritual of Homo Ludens." Journal of Contemporary Ethnography 5(3): 293-312.

Davis, Fred. 1959. "The Cabdriver and His Fare: Facets of a Fleeting Relationship." American Journal of Sociology 65(2): 158-165.

Dourish, Paul, and Genevieve Bell. 2007. The infrastructure of experience and the experience of infrastructure: meaning and structure in everyday encounters with space. Environment and Planning B: Planning and Design, 34(3), 414-430.

Duff, Cameron. 2005. Party drugs and party people: examining the "normalization"of recreational drug use in Melbourne, Australia. International Journal of Drug Policy, 16(3), 161-170. Elsevier.

Goffman, Erving. 1959. The Presentation of Self in Everyday Life. Garden City, NY: Anchor Books.

Goffman, Erving. 1967. Interaction Ritual. Garden City: Doubleday.

Granovetter, Mark. 1983. "The Strength of Weak Ties: A Network Theory Revisited." Sociological Theory 1(1): 201-233.

Grazian, David. 2007. "The Girl Hunt: Urban Nightlife and the Performance of Masculinity as Collective Activity." Symbolic Interaction 30(2): 221-243.

Hampton, Keith N. 2007. "Neighborhoods in the Network Society: The e-Neighbors Study." Information, Communication \& Society 10(5): 714-748.

Hampton, Keith N. 2011. "Comparing Bonding and Bridging Ties for Democratic Engagement: Everyday Use of Communication Technologies Within Social Networks for Civic and Civil Behaviors." Information, Communication \& Society 14(4): 510-528.

Hampton, Keith N., Oren Livio, and Lauren Sessions Goulet. "The Social Life of Wireless Urban Spaces: Internet Use, Social Networks, and the Public Realm.” Journal of Communication 60(4): 701-722.

Hampton, Keith N. and Barry Wellman. 2003. "Neighboring in Netville: How the Internet Supports Community and Social Capital in a Wired Suburb." City and Community 2(4): 277-311.

Henslin, James M. 1968. "The Cab Driver: An International Analysis of Occupational Culture.” Doctoral Dissertation, ProQuest Information \& Learning. 
Humphreys, Lee. 2005. Cellphones in public: social interactions in a wireless era. New Media \& Society, 7(6), 810. SAGE Publications.

Ito, Mizuko, Misa Matsuda and Daisuke Okabe. 2006. Personal, portable, pedestrian: Mobile phones in Japanese life. The MIT Press.

Katovich, Michael A. and William A. Reese II. "The Regular: Full-Time Identities and Memberships in an Urban Bar." Journal of Contemporary Ethnography 16(3): 308-343.

Laumann, Edward O., Stephen Ellingson, Jenna Mahay, Anthony Paik and Yoosik Youm, eds. 2004. The Sexual Organiztion of the City. Chicago: University of Chicago Press.

Liebow, Elliott. 1967. Tally's Corner: A Study of Negro Streetcorner Men. Boston: Little.

Lin, Ken-Hou and Jennifer Lundquist. 2013. "Mate Selection in Cyberspace: The Intersection of Race, Gender, and Educaiton.” American Journal of Sociology. 119(1): 183-215.

Lofland, John, David A. Snow, Leon Anderson, and Lyn H. Lofland. 2005. Analyzing Social Settings: A Guide to Qualitative Observation and Analysis (p. 282). Wadsworth Publishing.

Marlow, Cameron Alexander. 2005. "The Structural Determinants of Media Contagion." Doctoral Dissertation, MIT.

McFarland, Kathy Lou. 1974. Hauser's Place: An Ethnography of a Businessmen's Bar. Master's thesis, University of Houston.

Moore, E. C. 1897. "The social value of the saloon." American Journal of Sociology 3:1-12.

Morrill, Calvin, David A. Snow, and Cindy White. 2005. Together alone: personal relationships in public places. University of California Press.

Pasko, Lisa. 2002. "Naked power: The practice of stripping as a confidence game." Sexualities 5(1): 49-66.

Robnett, Belinda and Cynthia Feliciano. 2011. "Patterns of Racial-Ethnic Exclusion by Internet Daters." Social Forces 89(3): 807-828.

Rosenfeld, Michael J., and Rueben J. Thomas. 2012. "Searching for a Mate: The Rise of the Internet as a Social Intermediary." American Sociological Review 77(4): 523-547.

Simmel, Georg. 1949. "The sociology of sociability." American Journal of Sociology 55: 254261.

Snow, David A. and Leon Anderson. 1993. Down on their luck: A study of homeless street people. Berkeley: University of California Press.

Snow, David A., Cherylon Robinson, and Patricia L. McCall. 1991. "Cooling Out" Men in Singles Bars and Nightclubs: Observations on the Interpersonal Survival Strategies of Women in Public Places. Journal of Contemporary Ethnography, 19(4), 423-449.

Snow, David A., Louis A. Zurcher, and Gideon Sjoberg. 1982. "Interviewing By Comment: An Adjunt to the Direct Question." Qualitative Sociology 5(4): 285-311.

Steinfeld, Charles, Nicole B. Ellison, and Cliff Lampe. 2008. "Social Capital, Self-Esteem, and Use of Online Social Network Sites: A Longitudinal Analysis." Journal of Applied Developmental Psychology 29(6): 434-445.

Swidler, Ann. 2001. Talk of Love: How Culture Matters. Chicago: University of Chicago Press.

Toiskallio, Kalle. 2000. "Simmel Hails a Cab: Fleeting Sociability in the Urban Taxi." Space and Culture 3(6): 4-20.

Tufekci, Zeynep. 2010. "Who Acquires Friends Through Social Media and Why? Rich Get Richer Versus Seek and Ye Shall Find. ICWSM.

Waller, Willard. 1937. "The Rating and Dating Complex." American Sociological Review 2(5): 727-34. 
Wang, Hua and Barry Wellman. 2010. "Social Connectivity in America: Changes in Adult Friendship Network Size from 2002 to 2007." American Behavioral Scientist 53(8): 11481169.

Wellman, Barry, Anabel Quan Haase, James Witte, and Keith Hampton. 2001. "Does the Internet Increase, Decrease, or Supplement Social Capital? Social Netowrks, Participantion, and Community Commitment." American Behavioral Scientist 45(3): 436-455.

Weiser, Mark. 1993. Ubiquitous computing. IEEE Computer, 26(10), 71-72. 
Table 1: Bar Settings, by Sexuality and Locale

\begin{tabular}{lll}
\hline & \multicolumn{1}{c}{ Sexuality } & \multicolumn{1}{c}{ Locale } \\
\cline { 2 - 3 } Bar 1 & Heterosexual & Suburban \\
Bar 2 & Heterosexual & Suburban \\
Bar 3 & Gay Men & Suburban \\
Bar 4 & Gay Men & Urban \\
Bar 5 & Gay Men & Urban \\
Bar 6 & Gay Men & Urban \\
Bar 7 & Lesbian & Urban \\
\hline
\end{tabular}

